\title{
Entrepreneurship
}

Entrepreneurship

\section{A interdisciplinaridade da profissão biólogo}

Este trabalho tem como objetivo discutir e analisar a partir de trabalhos já publicados acerca da profissão de biólogo. Trata-se de uma revisão bibliográfica baseada em artigos selecionados no Google Acadêmico. Os estudos encontrados sobre a profissão de biólogo constataram que devido à formação multidisciplinar do biólogo, este profissional tem encontrado cada vez mais espaço no mercado de trabalho, abrangendo várias áreas biológicas, que consequentemente concorrem com outros profissionais com formação mais específica, como biomédicos, bioquímicos e veterinários. Os biólogos constituem papel fundamental na sociedade em geral assumindo a responsabilidade de formadores de mentes críticas e no progresso da ciência desempenhando estudos e descobertas que auxiliem na manutenção da vida no ecossistema.

Palavras-chave: Biólogo; Profissional; Atuação; Formação.

\section{The interdisciplinarity of the biologist profession}

The objective of this work is to discuss and analyze the work already published about the profession of biologist. This is a bibliographic review based on selected articles in Google Scholar. The studies found on the profession of biologist found that due to the multidisciplinary training of the biologist, this professional has been finding more space in the labor market, covering several biological areas, which consequently compete with other professionals with more specific training, such as biomedical, biochemical And veterinarians. Biologists play a fundamental role in society at large by taking on the responsibility of critical mind trainers and the advancement of science by carrying out studies and discoveries that assist in maintaining life in the ecosystem.

Keywords: Biologist; Professional; Acting; Formation.

\section{Topic: Recursos Humanos}

Reviewed anonymously in the process of blind peer.
Received: 06/08/2017

Approved: 11/11/2017
Larissa Leonilda Pereira Melo

Faculdade Guaraí, Brasil

http://lattes.cnpq.br/3718727871269178

larissalpmelo@gmail.com

Aluísio Vasconcelos Carvalho (iD)

Faculdade Guaraí, Brasil

http://lattes.cnpq.br/5200758055263996

http://orcid.org/0000-0002-3793-3133

aluisiovasconcelos@gmail.com

Ana Paula Martins Guimarães

Faculdade Guaraí, Brasil

http://lattes.cnpq.br/5309168123830683

biologa.apmg@gmail.com
Referencing this:

MELO, L. L. P.; CARVALHO, A. V.; GUIMARÃES, A. P. M.. A interdisciplinaridade da profissão biólogo. Entrepreneurship, v.1, n.1, p.28-33, 2017. DOI: http://doi.org/10.6008/SPC2595$\underline{4318.2017 .001 .0003}$ 


\section{INTRODUÇÃO}

A constituição de uma profissão é algo que permeia a vida em sociedade, responsável pela interação do indivíduo com os demais e sua contribuição para com determinado grupo social. A padronização de uma profissão evidencia uma entidade que se dá ao redor de concepções específicas e de uma unidade interna (BARBOSA, 1993) que na estrutura social e utilizando-se do conhecimento especializado é atribuída a uma determinada função.

A profissão de biólogo nem sempre teve essa denominação, sendo por muitos anos conhecida no Brasil como historiador natural ou naturalista. A profissão de biólogo foi regulamentada pela Lei n. 6.684 em 03 de setembro de 1979 quando também foi criado o Conselho Federal de Biologia - CFBio e os Conselhos Regionais de Biologia - CRBios pelo presidente da república João Baptista Figuereido (BRASIL, 2017).

O biólogo pode atuar nas áreas de meio ambiente e diversidade, saúde, e biotecnologia e produção, que podem abranger a área da educação e/ou pesquisa. Esse profissional deve ser atualizado e ter pleno domínio dos princípios e teorias da biologia, possuindo capacidade para atuar na elaboração e execução de projetos relacionando ciência, tecnologia e sociedade considerando as implicações de seus conhecimentos e de seu uso para a sociedade (OLIVEIRA et al, 2007). É essencialmente importante que o biólogo goste de estudar animais, plantas e tudo que está relacionado à vida. Biologia é uma palavra formada pelos termos gregos "bios" vida e "logos" estudo, portanto a biologia significa literalmente o estudo da vida.

Com os avanços tecnológicos e crescentes índices de devastação ambiental os desafios a serem enfrentados pelos biólogos foram multiplicados, porém a situação deve ser enfrentada com uma visão crítica em prol da saúde geral para melhorar a qualidade de vida no planeta, realizando ações que colaborem com a preservação das espécies, a sustentabilidade e a conservação da vida (RIBEIRO, 2015). Sendo assim tem-se feito cada vez mais necessário o exercício das funções do biólogo devido à degradação humana causada ao ecossistema.

De forma simultânea, o biólogo atua também como educador afim de formar indivíduos capazes de refletir seu vínculo com o ambiente no qual se inserem, respeitando, colaborando e apoiando o ambiente a manter a vida correlacionando seu estilo de viver (KRAHENBUHL, 2010). Consequentemente pode-se afirmar que este profissional em questão possui uma gama de responsabilidades, tanto com a sociedade, o ecossistema e toda a vida que habita no planeta. Portanto o exercício de suas atividades irá repercutir no que diz respeito a permanência de todas as espécies que povoam a Terra.

Em vista disso, este artigo de revisão propõe-se a reunir, de diversos trabalhos publicados que envolvem a temática, várias perspectivas acerca da profissão de biólogo e o impacto socioambiental de suas funções para que dessa forma seja possível analisar e discutir as diferentes facetas existentes. Pretende-se informar tanto a sociedade em geral, como os acadêmicos que estejam cursando uma graduação em Ciências Biológicas, em relação a relevância da atuação do biólogo e seu papel para com a vida. 


\section{METODOLOGIA}

Com a principal finalidade de aprimorar ideias ou descobertas, que consiste em um estudo de revisão teórica, abrangendo um levantamento bibliográfico (GIL, 2002), foi utilizado para o presente trabalho. Para a pesquisa bibliográfica fez-se o emprego de artigos que foram procurados com o auxílio da ferramenta Google Acadêmico com a utilização das palavras-chave "biólogo", "profissão", "atuação", "biologia" e "sociedade". Realizou-se busca em sites federais como o do Conselho Federal de Biologia - CFBio.

Buscou-se estudar e compreender as principais concepções que envolvem a profissão de biólogo, como áreas de atuação, importância social, perfil exigido do profissional, principais dificuldades encontradas para o exercício da função entre outros.

\section{REVISÃO DA LITERATURA}

\section{Biólogo na saúde}

Frequentemente, torna-se indispensável para o estudo epidemiológico de uma doença ou epidemia, o conhecimento adquirido pelo biólogo sobre a diversidade biológica, o que reflete nas decisões a serem tomadas para o seu controle (FORATTINI, 1989). Com a inserção do biólogo na área da saúde, muitos avanços forma feitos na ciência advindos das pesquisas e descobertas.

A atuação do biólogo na área da saúde foi reconhecida pelo Conselho Nacional de Saúde na Resolução no 287 de 08 de outubro de 1998, passando a ser legalmente uma "categoria profissional de saúde de nível superior". O trabalho realizado pelos biólogos está intimamente ligado à saúde coletiva, pois segundo Bastos (2007) eles procuram melhorar a qualidade de vida através de projetos, atividades e trabalhos que colaborem com a manutenção e conservação, manejo e melhoramento de microrganismos e do meio ambiente e à Educação Ambiental.

Há várias áreas de atuação para o biólogo na saúde, como por exemplo, análises clínicas, bioética, controle de vetores e pragas, perícia e biologia forense, gestão de bancos de células e material genético e outros. O biólogo como profissional tem o dever de atuar com responsabilidade visando a melhoria da qualidade de vida e agindo de acordo com o perfil elaborado pelas Diretrizes Curriculares Nacionais (DCN's).

\section{Biólogo Pesquisador}

As pesquisas estão intimamente ligadas ao aperfeiçoamento da ciência e são fundamentais para o progresso da humanidade. É uma forma de investigar para obtenção de conhecimento científico, que posteriormente será utilizada por colegas de profissão que se justificam em experimentos com base nas teorias que baseiam os paradigmas científicos aceitos no período de ciência normal (KUHN, 1975). A pesquisa biológica é divida em três tipos: a de campo, a de laboratório e a de fronteira.

Pesquisas feitas em ambiente laboratorial por cientistas objetivam o convencimento da importância e da veracidade dos seus projetos (LATOUR \& WOOLGARL, 1987). Autores como Steve Woolgar e Bruno Latour (1979), Michael Lynch (1985) e Karin Knorr-Cetina (1981) alegam que o laboratório, além de tratar-se 
de um lugar de produção de conhecimento é também um ambiente de construção de fatos que constituem práticas da vida social.

Já as pesquisas realizadas em campo, dadas as dificuldades de controle do ambiente, apresentam uma maior complexidade com a credibilidade e reconhecimento da pesquisa, devido a falta de domínio exclusivamente científico (KUKLICK \& KOHLER, 1996). A estratégia utilizada para esse impasse é adequar às condições de campo os elementos da prática laboratorial. Nas pesquisas de campo os estudos biológicos ainda estão voltados para a análise de uma área geográfica com a finalidade de elaborar seu levantamento científico e estudos evolutivos (ZARUR, 1994).

Já as pesquisas feitas em ambos os espaços de pesquisas citados são denominados de pesquisas de fronteiras, ou seja, em ambientes internos (laboratórios, museus) e ambientes externos (campo) (WEIHS, 2008). Trata-se de uma área de pesquisa mais complexa por exigir domínio das ferramentas de ambos os ambientes.

\section{Biólogo Professor}

O composto de práticas e elaborações que um docente precisa para realizar sua função é temática de diversos estudos quando muito se relaciona ao professor de ensino superior ou como professor especialista, contudo muitos desses estudos são realizados no contexto geral de professor (TARDIF, 2008; CANDAU, 1997; DEMO, 2007; PIMENTA, 2008; PERRENOUD et al, 2001). De acordo com Nóvoa (1999), "a formação de professores é, provavelmente, a área mais sensível das mudanças em curso no setor educativo: aqui não se formam apenas profissionais; aqui produz-se uma profissão".

No contexto da formação em Ciências Biológicas/Biologia, modalidade licenciatura, o profissional licenciado deve-se ater não somente aos conhecimentos específicos da área biológicas, pois isso gera professores despreparados para o mercado de trabalho (GORDERT apud ARAÚJO et al, 2007). Atualmente é exigida do docente biólogo uma vasta e abrangente formação que possibilite a compreensão das relações existentes entre os seres vivos e o ambiente que são evidenciadas por interações e mutualidade que não podem ser estudadas de maneira isolada. Então além das disciplinas específicas pertinentes à atuação do biólogo, o foco da formação nos cursos de Ciências Biológicas deve abranger a profissionalização docente para que o futuro professor seja um transformador social.

O professor constrói seus conhecimentos de conforme sua identidade e com suas experiências. A carga de conhecimentos do docente expande-se ao longo de suas experiências. O professor necessita possuir numerosas capacidades, inclusive para fazer com que o aluno se desenvolva e aprenda. Além disso, precisa ser capaz de articular-se dentro do seu grupo, ser capaz de lidar com as diferenças e sempre se auto avaliando (MELLO, 2001). Para isso é necessária uma educação centralizada na prática da ciência e que repudie o conceito de ciência inerte, pois está sempre está sob constantes modificações advindas dos variados estudos e descobertas. 


\section{Biólogo Conservacionista/Ambientalista}

As alterações e pressões em que o ambiente vem sofrendo em decorrência das atividades antrópicas tem contribuído para o surgimento de profissões elencadas na preocupação ambiental. As atividades desenvolvidas por estas profissões têm por objetivo gerar a consciência ambiental nas populações vulneráveis, um trabalho contínuo para o progresso da integridade do ambiente e suas inter-relações. Em primeira instância, percebe-se uma visão naturalista em que a paisagem é constituída de elementos geomorfológicos, fauna, flora e suas relações ecológicas; em segundo, percebe-se a ação da espécie humana sobre esse ambiente quebrando as cadeias naturais destes ambiente alterando a dinâmica de tais elementos (MELAZO, 2005).

A profissão biólogo atua em conjunto com outras profissões a ciência ambiental buscando despertar a curiosidade nas pessoas (público-alvo) e sua participação no combate a degradação ambiental (ABRAMOVAY, 2002).

As atividades de educação ambiental, seja formal (aquela em que o público alvo é a escola e suas atividades são desenvolvidas nela) ou informal (dedicada a população em geral, possui uma visão mais comercial devido sua natureza está relacionada às empresas e suas atividades impactantes), tem ganhado força na profissão biólogo através dos projetos socioambientais para mitigação ambiental.

\section{CONCLUSÃO}

Biólogo é todo portador de diploma em Ciências Biológicas que esteja em situação regular junto ao Conselho que regulamenta o exercício de sua profissão. No caso dos licenciados, eles estão habilitados a atuar, também, em sala de aula da Educação Básica a Superior. Sabe-se também que a cada instante as áreas de atuação para o biólogo se expandem, já que este profissional pode exercer suas funções em outros ambientes como: museus, parques, zoológicos, laboratórios de exames biológicos e patológicos, áreas de proteção ambiental, secretarias de meio ambiente, escolas, universidades.

A profissão de biólogo envolve uma ampla gama de conhecimentos multidisciplinares que possibilita sua atuação em diversas áreas, dependendo de sua formação e habilitação. A Biologia é a ciência responsável pelo estudo dos seres vivos e seus aspectos, estudo esse que sempre tende a buscar a melhoria da qualidade de vida. Os biólogos também possuem um importante papel a desempenhar para com a sociedade, são formadores e transformadores de mentes pensantes, contudo, para que isso ocorra é necessário que o biólogo instigue em seus alunos ou na sociedade em geral o espírito crítico e reflexivo acerca de questões biológicas.

O curso de Biologia/Ciências Biológicas tem no Brasil a duração média de 4 a 5 anos, podendo ser licenciatura ou bacharelado. O mercado de trabalho encontra-se bastante receptível para o profissional biólogo, destacando que em muitas áreas de atuação ainda há a necessidade de valorizar mais essa função, porém para o profissional comprometido com seu dever para com a vida e que possui o perfil esperado para 
sua profissão sempre está apto a desempenhar seu papel e colaborar com a manutenção e melhora da qualidade de vida.

\section{REFERÊNCIAS}

ABRAMOVAY, R.. Construindo a ciência ambiental. Annablume, 2002.

ARAÚJO, W. S.; ÀVILA, D. R.; FALEIRO, F. A. M. V.; MAZARO, R.. Formação acadêmica e identidade profissional de formandos do curso de Ciências Biológicas do ICB/UFG. In: Revista Solta a Voz, v.18, n.2, p.243-254, 2007.

BARBOSA, M. L. O.. A Sociologia das Profissões: em Torno da Legitimidade de um Objeto. BIB, n.36, p.3-30, 1993.

BASTOS, C. M. L. F.. O Biólogo, a Pesquisa Biomédica e o Meio Ambiente: A Importância do Biólogo no meio Biomédico e a Relação do Meio Ambiente com a Saúde. Revista Eletrônica de Ciências, n.39, 2007.

BRASIL. Conselho Federal de Biologia. Histórico da Profissão. Brasília: CFBio, 2017.

CANDAU, V. M. F.. Universidade e formação de professores: que rumos tomar?. In: CANDAU, V. M. F.. Magistério: construção cotidiana. Petrópolis: Vozes, 1997.

DEMO, P.. Educar pela pesquisa. 8 ed. Campinas: Autores Associados, 2007.

FORATTINI, O. P.. Biosystematics and Public Health. Revista de Saúde Pública, v.23, n.3, p.181-182, 1989.

GIL, A. C.. Como Elaborar Projetos de Pesquisa. 4 ed. São Paulo: Atlas, 2002.

GOMES, A. M. A.; MOURA, E. R. F.; AMORIM, R. F.. O lugar da ética e bioética nos currículos de formação médica. Revista Brasileira de Educação Médica, Rio de Janeiro, v.30, n.2, p.56-65, 2006.

KUHN, T. S.. A Estrutura das Revoluções Científicas. São Paulo: Perspectiva, 1975.

KUKLICK, H.; KOHLER, R. E.. Introduction: Science in the Field. OSIRIS, v.11, n.1, p.1-14, 1996.

KRAHENBUHL J. L.. Educação ambiental. Rev. BioBrasilis, v.1, n.1, p.17-20, 2010.

LATOUR, B.; WOOLGAR, S.. Laboratory life: The construction of scientific facts. San Diego: Sage, 1979.
LATOUR, B.; WOOLGAR, S.. A Vida de Laboratório: a produção dos fatos científicos. Rio de Janeiro: Relume Dumará, 1987.

MELAZO, G. C.. Percepção ambiental e educação ambiental: uma reflexão sobre as relações interpessoais e ambientais no espaço urbano. Olhares \& Trilhas, Uberlândia, v.6, n.6, p.45-51, 2005.

MELLO, G.. Formação inicial de professores para a Educação Básica: uma (re)visão radical. Revista Iberoamericana de Educación, Madrid, n.5, p.147-174, 2001.

NÓVOA, A.. Profissão professor. 2 ed. Porto: 1999.

OLIVEIRA, I. B.; SILVA, L. O.; SOUZA, J. M. H. E.; GOMES, J. P.; LUCENA, L. R. F.; AMARAL, W. S.; VASCONCELOS, S. D. Avaliação das percepções e expectativas de bacharelandos em biologia: perfil e regulamentação profissional. Rev. Estudos em Avaliação Educacional, v.18, n.36, p.167-80, 2007.

PERRENOUD, P.. Formando professores profissionais: três conjuntos de questões. In: PAQUAY, L.. Formando professores profissionais: quais estratégias? Quais competências?. 2 ed. Porto Alegre: Artmed, 2001.

PIMENTA, S. G.. Formação de professores: identidade e saberes da docência. In: PIMENTA, S. G.. Saberes pedagógicos e atividade docente. 6 ed. São Paulo: Cortez, 2008.

RIBEIRO, C. M.. Biossegurança: abordagem cognitiva essencial para o biólogo. 2015.

TARDIF, L.. Saberes docentes e formação profissional. 9 ed. Petrópolis: Vozes, 2008.

WEIHS, M. L.. A produção de conhecimento em biologia: uma pesquisa edtnografia. Dissertação (Mestrado em Geociências) - Universidade Estadual de Campinas, Campinas, 2008.

ZARUR, G. C. L.. A arena científica. Campinas: Autores Associados, 1994. 